\title{
Diagnosis and pharmacotherapy of severe acute respiratory syndrome: what have we learnt?
}

\author{
K.W. Tsang*, G.C. Ooi ${ }^{\top}$, P.L. Ho ${ }^{\#}$
}

Diagnosis and pharmacotherapy of severe acute respiratory syndrome: what have we learnt? K.W. Tsang, G.C. Ooi, P.L. Ho. C) ERS Journals Ltd 2004.

ABSTRACT: In 2003, the onset of severe acute respiratory syndrome (SARS) caused worldwide chaos. Although SARS was eradicated by isolation towards the end of 2003, sporadic cases have been reported in Singapore, Taiwan and mainland China.

In this review, SARS is discussed as a disease, as well as its diagnosis, management and pharmacotherapy.

Respiratory physicians and healthcare professionals have to be aware of advances in the understanding of the diagnosis and management of severe acute respiratory syndrome. More research is required in order to prepare for if this respiratory infection recurs, but there are concerns that adequate pharmaceutical support may be lacking for the development of a vaccine.

Eur Respir J 2004; 24: 1025-1032.
Depts of *Medicine, ${ }^{*}$ Microbiology, and Diagnostic Radiology, University of Hong Kong, Hong Kong SAR, China.

Correspondence: K.W.T. Tsang, Dept of Medicine, The University of Hong Kong, Queen Mary Hospital, Pokfulam, Hong Kong SAR, China.

Fax: 85229049443

E-mail: kwttsang@hku.hk

Keywords: Diagnosis, severe acute respiratory syndrome, treatment

Received: August 42004

Accepted: August 92004

\section{The 2003 outbreak}

The worldwide panic and chaos surrounding the onset of severe acute respiratory syndrome (SARS) in 2003, caused by a novel coronavirus (SARS-CoV), was unprecedented in the 21 st century. SARS had claimed the lives of 774 among 8,098 affected cases scattered in 29 countries on all five continents [1]. Although eradicated by effective isolation eventually in the latter part of 2003, there have still been sporadic cases reported among laboratory workers in Singapore, Taiwan and the mainland of China [2-4]. Whilst it was fortunate that none of these sporadic cases had spread to the community, thus causing widespread outbreaks again, respiratory physicians and healthcare professionals have to be aware of recent advances in the understanding of the diagnosis and management of SARS, amid thousands of publications amassed over the last 12 months.

\section{Severe acute respiratory syndrome as a disease}

There are three nondistinct and highly individualised phases of SARS as the illness unfolds, namely, viral replication, inflammatory pneumonitis and pulmonary fibrosis, which conceptually might warrant different modes of treatment. Shedding of SARS-CoV, evaluated by RT-PCR on 2,134 nasopharyngeal aspirates and faeces, shows positive rates, peaking at 6-11 days after the onset of illness for nasopharyngeal aspirates $(58-60 \%)$ and 9-14 days for faeces $(68-70 \%)$. Overall, peak viral loads were reached at 12-14 days of illness [5]. Therefore, antiviral therapy should be instituted in the early phases of the illness to coincide with this time frame.

Autopsy studies of the lungs of 29 patients show diffuse alveolar damage, secondary bacterial pneumonia, and giant-cell and macrophages infiltration into the alveoli and lung interstitia, but no conclusive diagnostic features [6-9]. Nonetheless, these changes might merely represent end-stage disease, rather than the pathogenesis of earlier and more treatable SARS-CoV pneumonitis. In a series of eight SARS patients undergoing autopsy examination, 50\% displayed gross signs of pulmonary thromboemboli, whilst one patient had marantic cardiac valvular vegetations [6]. These findings have particular therapeutic implications in view of the perceived low frequency of pulmonary thromboemboli among Orientals.

A more recent autopsy report on seven SARS patients also showed resemblance of SARS pathologically to bronchiolitis obliterans organising pneumonia (BOOP), namely in the presence of fibrogranulation tissue proliferation in small airways and airspaces (BOOP-like lesions) in subpleural locations. The predominately peripheral and lower-zone consolidation of some SARS patients was also radiographically highly reminiscent of BOOP [10]. While BOOP is an increasingly recognised steroid-responsive pneumonitis, which could be related to underlying immune disorders, these pathological and radiological similarities suggest an immunological element in the pathogenesis of SARS pneumonitis [11]. The pathogenesis for the other manifestations of SARS is largely known, although it is likely that SARS-CoV is a systemic illness with less severe extrapulmonary effects (table 1).

\section{Diagnosis of severe acute respiratory syndrome}

Diagnostic criteria proposed by the World Health Organization (WHO) and Centers for Disease Control and Prevention (CDC) are predominantly epidemiologically orientated, and rely heavily on positive identification of SARS-CoV [17, 18] by using serology and RT-PCR. Thus, these criteria are not useful at the bedside, although the principle of clinical 
Table 1.-Clinical manifestations of severe acute respiratory syndrome

Pulmonary $[7,8]$

Thrombosis of vessels

Fibrosis

Restrictive lung defect

Traction bronchiectasis

Neurological [12-14]

Inability to concentrate

Depression and anxiety

Peripheral nerve disease

Detection of SARS-CoV RNA in cerebrospinal fluid

Psychological distress

Liver function disruption [15]

Cardiac complications [6]

Diastolic dysfunction

Sudden death

Pulmonary thromboembolism

Marantic cardiac valvular vegetations

Diarrhoea [10]

Rhadomyolysis [16]

Thrombocytopenia [10]

Avascular necrosis of femoral head

SARS-CoV: severe acute respiratory syndrome coronavirus.

diagnosis followed by virological confirmation of SARS-CoV infection is mandatory.

\section{Bedside and clinical diagnosis of severe acute respiratory syndrome}

Clinical alertness leading to a suspicion or diagnosis of SARS will not only be important for the patient, but also for the healthcare workers who are themselves at grave risk. The clinical features of SARS are shown in table 2. These features are not specific and do not necessarily help to diagnose SARS from many other patients with non-SARS pneumonias, especially those caused by the conventional "atypical organisms", such as Mycoplasma pneumoniae or Chylamdia pneumoniae. There is little evidence of widespread subclinical or mild forms of SARS-CoV infection, although some patients with an immunocompromised state might present with indolent and, thus, less typical features [23, 24]. SARS also seems to run a less aggressive clinical course in younger children, and few children with such illness required oxygen therapy [25].

The key diagnostic process relies on the demonstration of an epidemiological linkage, presence of pneumonia resistant to treatment, and the presence of clinical features of SARS (table 3). It then follows that it is very difficult to diagnose the first or sporadic cases of SARS in a non-outbreak situation. While the prerequisites for diagnosis of confirmed SARS that are shown in table 3 are probably more specific than the diagnostic criteria released by CDC and WHO [17, 18], most respiratory physicians with experience in dealing with SARS patients also advocate observation of the clinical course of a patient.
Table 2. - Presenting symptoms for 385 patients $^{\#}$

Clinical features

Patients with symptom \%

\begin{tabular}{lc}
\hline Fever & 99.7 \\
Cough & 58.7 \\
Myalgia & 57.7 \\
Chills/rigor & 55.1 \\
Headache & 40.5 \\
Dizziness & 19.7 \\
Dyspnoea & 17.9 \\
Diarrhoea & 17.1 \\
Sore throat & 16.1 \\
Nausea/vomiting & 15.3 \\
Sputum production & 13.8 \\
Malaise & 13.5 \\
Rhinorrhoea & 10.1 \\
Chest pain/pleurisy & 4.7 \\
Arthralgia & 3.9 \\
Abdominal pain & 1.3 \\
\hline
\end{tabular}

\#: from reported case series [10, 19-22].

Evaluation of clinical features, themselves nonspecific, is probably useful in an outbreak situation, although probably less so for sporadic outbreaks or in the first encounter of an outbreak wave. Two retrospectively derived scoring systems, designed to demarcate SARS from other patients attending emergency rooms (ER) during the 2003 Taiwanese outbreak, have been published. The attribution of 3, 3, 2, 1, 1, 1, and 1 points was done in the presence of multi-lobar radiographical infiltration, sputum monocyte predominance, lymphopenia, epidemiological linkage, high lactate dehydrogenase, high Creactive protein, and high activated partial prothrombin time, respectively. At a cut-off of 6 points, the sensitivity and specificity in distinguishing SARS from other ER attendants, were 100 and $93 \%$ [26]. The second study showed that a fouritem symptom score, based on the presence of cough, myalgia, diarrhoea, and rhinorrhoea or sore throat, detected SARS $(\mathrm{n}=8)$ from non-SARS $(\mathrm{n}=70)$ patients with $100 \%$ sensitivity and $75.9 \%$ specificity [27]. The usefulness of these simplistic and overtly nonspecific clinical prediction rules remains to be validated.

The use of broad-spectrum antibiotics, such as the combination of a cephalosporin and a macrolide, was particularly useful in the 2003 outbreak as the resolution of fever, improvement in general well-being, resolution or stabilisation of radiographical consolidation, and improvement of lymphopenia or raised liver transaminases that follow virtually excludes SARS as the cause of community-acquired pneumonia (CAP) $[11,28]$. Almost all adult SARS patients deteriorate clinically and radiologically within 2-4 days after admission to hospital (fig. 1). Very few patients display resolution of fever or improvement of chest radiograph on admission.

Radiology is the most important mode to evaluate the lung consolidation, especially as physical examination of the chest does not yield any specific signs, other than those of consolidation. At fever onset, almost $80 \%$ of patients with SARS

Table 3. - Key features for diagnosis of severe acute respiratory syndrome (SARS)

Compatible clinical symptoms of respiratory illness (temperature: $>38^{\circ} \mathrm{C}$ ) and at least one respiratory feature (cough, dyspnoea, difficulty breathing, or hypoxia)

Presence of radiological evidence of consolidation

Failure to demonstrate a clinical or radiological response to potent antibiotic therapy

Otherwise unexplained and persistently abnormal lymphopenia and raised AST and ALT

Molecular or serological confirmation of SARS-CoV infection

History of contact with suspected or confirmed patients with SARS, or travelling history to at-risk areas, or history of contact with contaminated materials (laboratory workers)

SARS-CoV: severe acute respiratory syndrome coronavirus; AST: aspartate transaminase; ALT: alanine transaminase. 

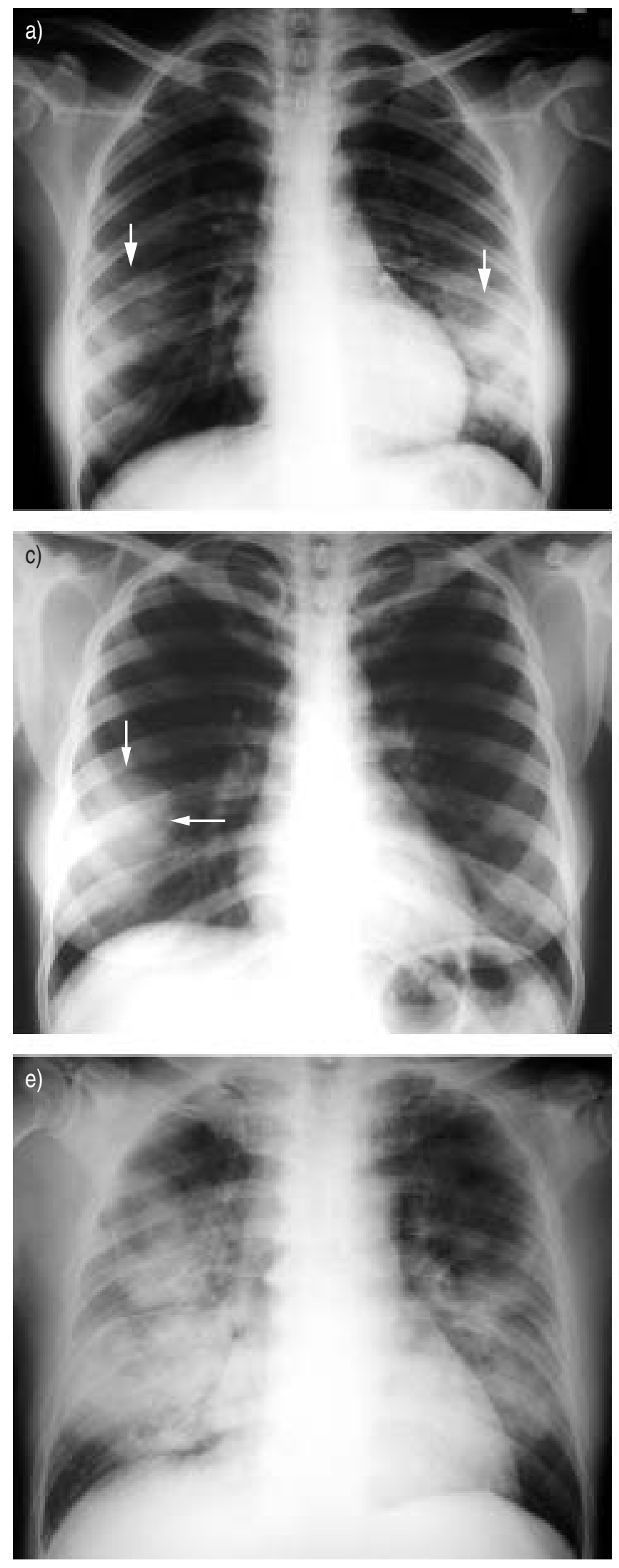

have abnormal chest radiographs, all of which show airspace consolidation that initially tends to be peripheral and lower zone in distribution [29-31]. Whilst most patients have abnormal chest radiograph on presentation, the patterns are
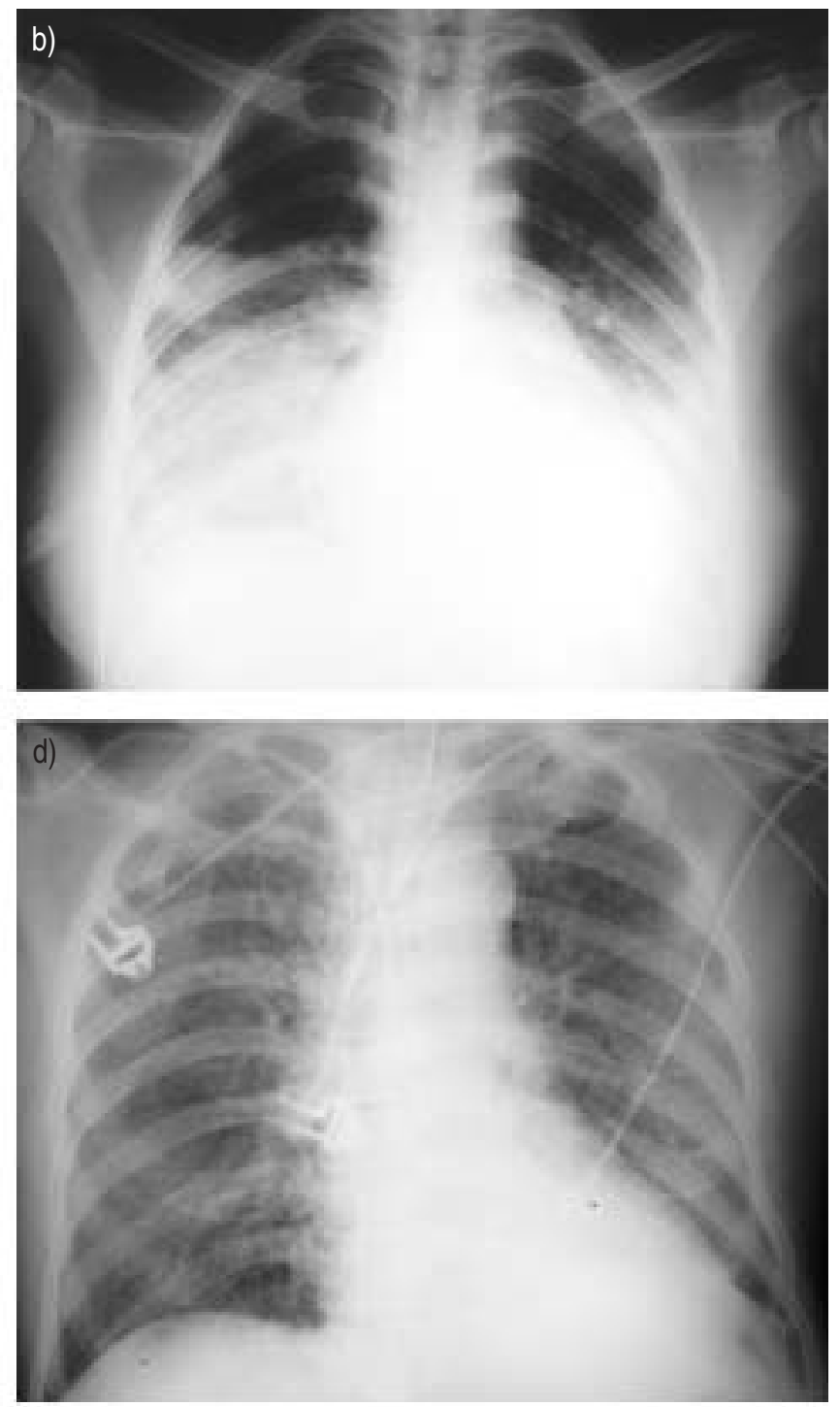

Fig. 1. - Five different radiographical patterns of severe acute respiratory syndrome (SARS) are shown. Chest radiographs at a) presentation and b) day 4 after admission of a 24 -yr-old female with SARS show rapid progression of patchy consolidation (arrows) in both lower zones to diffuse consolidation affecting both mid and lower zones. c) Chest radiograph of another female with SARS showing confluent consolidation (arrows) in the right lower zone. d) Chest radiograph of a 54-yr-old male with SARS showing small diffuse nodular opacities. e) Chest radiograph of a 38-yr-old male showing diffuse acute respiratory distress syndrome-type airspace opacities.

highly variable including: bilateral patchy consolidation (fig. 1a), nodular shadows (fig. 1b), diffuse acute respiratory distress syndrome (ARDS) type (fig. 1c), confluent consolidation (fig. 1d) and diffuse consolidation (fig. 1e). There is 
usually no cavitation, hilar lymphadenopathy or pleural effusion at presentation [32]. Generally, radiographical opacities peak 8-10 days after the onset of illness when bilateral disease is usually the case, and radiographic severity tends to correlate with clinical and laboratory parameters, such as oxygen saturation and liver transaminases [15, 30, 31]. Pneumomediastinum and pneumothoraces, often spontaneous but also occur with assisted ventilation, could complicate extensive disease (fig. 2) [33]. The presence of these conditions is highly suggestive of SARS, although they have also been reported to occur among patients infected with the highly virulent $\mathrm{H} 5 \mathrm{~N} 1$ strains of avian influenza (personal communication, C.M. Chu, United Christian Hospital, Hong Kong SAR, China).

A chest radiograph without infiltrates in the early stage of SARS is an important factor that is responsible for delayed diagnosis [28]. High-resolution computed tomography (HRCT) has a role in such cases in detecting radiographical occult airspace opacities when a patient has contact history and features suspicious of SARS (fig. 3). The characteristic HRCT features in the acute phase are ground-glass opacities with smooth interlobular septal thickening, sometimes with consolidation in a subpleural location, which progress within a few days to involve other areas. Temporal lung changes documented on HRCT suggest that some residual opacities found may not be reversible, thus accounting for residual pulmonary fibrosis and restrictive lung disease [30-32, 34, 35].

\section{Virological diagnosis of severe acute respiratory syndrome}

During the 2003 outbreak, the diagnosis of SARS relied heavily on clinical and epidemiological criteria. At that time, microbiological tests to identify SARS-CoV infection were immediately put into clinical use before any optimisation and validation. Antibody detection and RT-PCR for SARS-CoV specific nucleic acid are the most widely used tests. Due to the lack of a gold standard, it is still very difficult to assess the usefulness of these tests even today. Demonstration of seroconversion or a minimal four-fold rise in titre using immunofluorescence tests has been a reliable means for confirming the diagnosis. However, antibody response appears only around day 10-14 after onset of fever, and, in

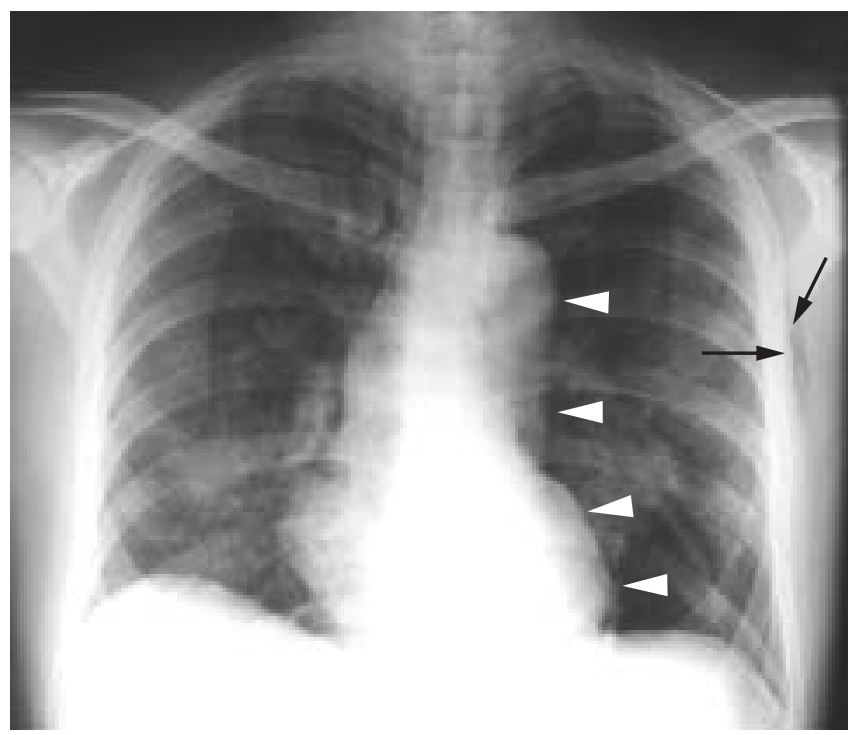

Fig. 2. - Chest radiograph showing pneumomediastinum (arrowheads) and surgical emphysema (arrows) in the left axilla. There are patchy areas of consolidation in both lower and mid-zones. some patients, it may take up to 21 or even 28 days [18] In equivocal cases, such as the recent laboratory-acquired situations, they could be valuable for establishing the diagnosis. Viral culture is still insensitive [36] and, again, suffers from the drawback of taking too long for bedside decisions. Hence, much effort has been put into the development and evaluation of rapid tests that yield a result within hours.

The reported sensitivity and specificity of the rapid SARS tests are summarised in table 4 . The evaluated specimen types include nasopharyngeal aspirate (NPA) or swab, throat swab, faeces and urine [36-43]. In the upper respiratory tract, the viral load is low in the 7 days and peaks at around day 10 of illness [22, 36, 40]. Thus, diagnostic tests for SARS should be compared with reference to the timing of collection. In the first 5 days of illness, respiratory specimens are the most useful for diagnosis. At this juncture, the newer generation of real-time PCR performed on NPAs is expected to have a sensitivity of $\sim 80 \%[41,42]$. Later in the disease, viral RNA could also be detected in other specimens, such as stool and urine [36]. Following optimisation, the detection limit of real-time PCR is around 10 RNA copies per reaction. The
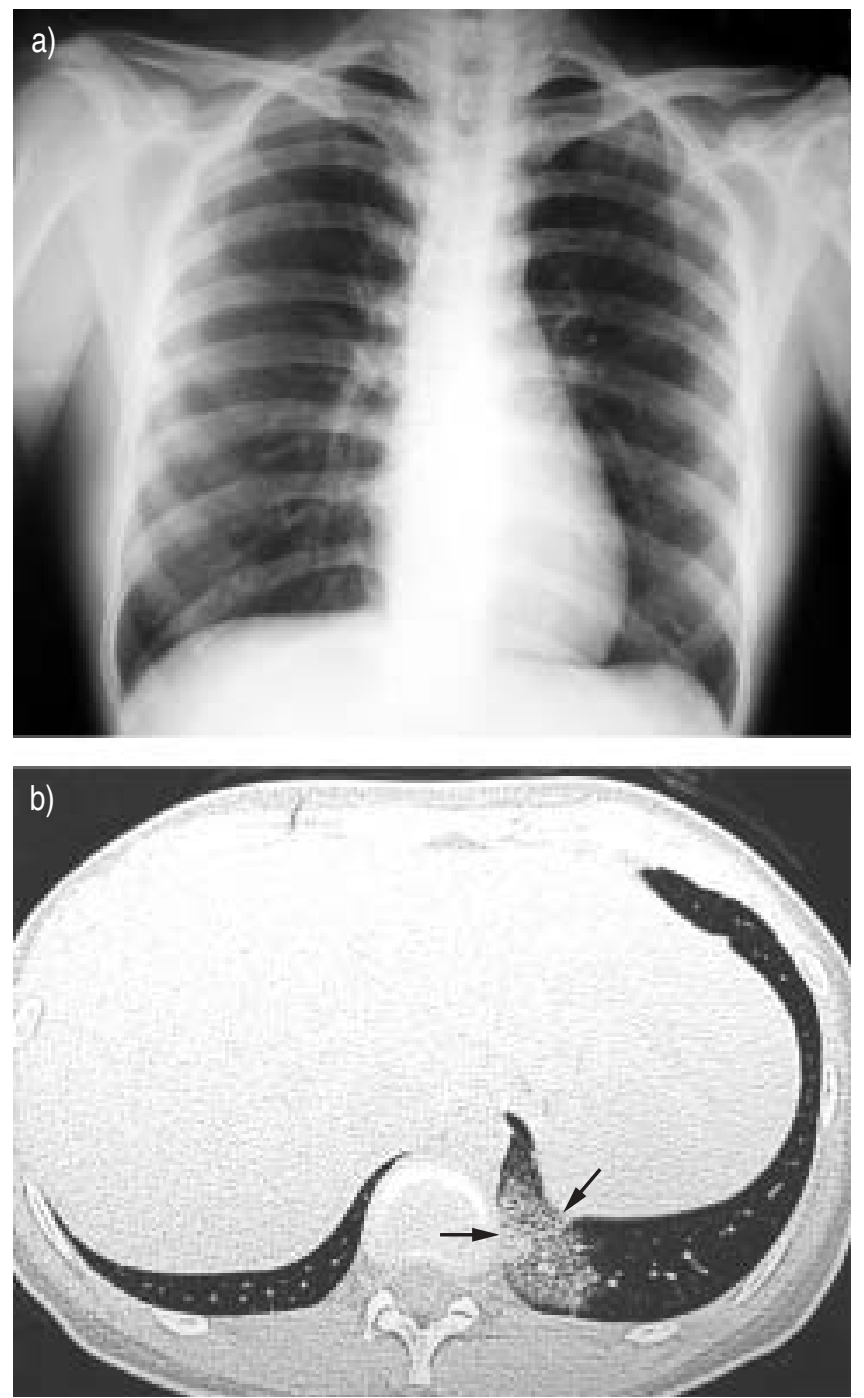

Fig. 3.-a) Chest radiograph of a 34-yr-old female with known exposure to severe acute respiratory syndrome on admission, showing no obvious abnormalities. b) High-resolution computed tomography was performed due to high index of suspicion and confirmed groundglass opacities (arrows) with smooth interlobular septal thickening in the left lung base. 
Table 4.-Summary of RT-PCR assays for laboratory diagnosis of severe acute respiratory syndrome (SARS)

\begin{tabular}{|c|c|c|c|}
\hline References & Method & Specimen types (number of samples) & Performance \\
\hline [37] & Real time RT-PCR & $\begin{array}{l}\text { NPA }(n=87) \text { from SARS and } \\
\text { non-SARS controls }\end{array}$ & Timing: NS; sensitivity: 79\%; specificity: 98\% \\
\hline [38] & Real time RT-PCR & $\begin{array}{l}\text { NPA, T/S, urine and stool }(n=303) \\
\text { from suspected SARS }\end{array}$ & $\begin{array}{l}\text { Timing: respiratory specimens (1-5 days } \\
\text { after admission), urine and stool } \\
\text { (5-10 days after admission); sensitivity: } \\
61 \text { and } 68 \% \text { (respiratory), } 50 \text { and } 54 \% \\
\text { (urine), } 58-63 \% \text { (stool); specificity: } 100 \%\end{array}$ \\
\hline [39] & RT-PCR (nested) & $T / S(n=46)$ from suspected SARS & Timing: NS; sensitivity: $37 \%$ \\
\hline [40] & Real time RT-PCR & NPA $(n=170)$ & $\begin{array}{l}\text { Sensitivity: } 26 \%(\text { day } 1-3), 41 \% \text { (day } 4-6) \text {, } \\
\quad 62 \%(\text { day } 7-10)\end{array}$ \\
\hline [36] & Real time RT-PCR & $\begin{array}{l}\text { NPA, respiratory swabs, sputum, } \\
\text { stool, urine (SARS: } n=200 \\
\text { non-SARS: } n=671 \text { ) }\end{array}$ & $\begin{array}{l}\text { Timing: day } 1-5 \text { after disease onset; sensitivity: } \\
31 \% \text { (respiratory specimens), } 20 \% \text { (stool), } \\
0 \% \text { (urine) }\end{array}$ \\
\hline [41] & $\begin{array}{l}\text { RT-PCR (real time with } \\
\text { internal control) }\end{array}$ & $\begin{array}{l}\text { NPA (SARS: n=86; non-SARS: } \\
\text { n=24) }\end{array}$ & $\begin{array}{l}\text { Sensitivity: } 96.6 \% \text { (day } 1-3 \text { ), } 80.7 \% \text { (day 4-9); } \\
\text { specificity: } 100 \%\end{array}$ \\
\hline [42] & Real time RT-PCR & NPA (SARS: $n=50)$ & Sensitivity: $80 \%$ (day $1-3$ ) \\
\hline [43] & Real time RT-PCR & T/S (SARS: $n=590)$ & Sensitivity: $32 \%$ (day 1 ), $50-60 \%$ (day $7-10$ ) \\
\hline
\end{tabular}

NPA: nasopharyngeal aspirate; NS: not specified; T/S: throat swab.

utility of serum or plasma as a diagnostic specimen remains to be examined, as too few specimens had been evaluated [44].

\section{Management of severe acute respiratory syndrome}

The treatment for SARS is largely anecdotal, and there are no controlled trial data to confirm or refute the efficacy of the treatment modalities.

\section{Pharmacotherapy of severe acute respiratory syndrome}

Theoretically, none of the manifestations of SARS should occur if an efficacious antiviral agent is given at the beginning of the illness. However, agents of proven efficacy are not available, despite prolific suggestions on clinically untried agents (table 5). The current logical step to take would be, other than empirical antibiotic therapy for severe CAP (such as the combined use of a cephalosporin and a macrolide, or a fluroquinolone), to undertake controlled clinical trials to evaluate the efficacy of potential antiviral and immunomodulating agents. The latter appear to be useful as rescue therapy should a patient deteriorate in spite of antiviral therapy. Clinical experience has only been available on a few agents used in the 2003 outbreak, namely, ribavirin, Kaletra (ritonavir/lopinavir), interferons (IFN), corticosteroids, convalescence serum, and immunoglobulin (Ig).

Table 5.-Potential agents for treatment of severe acute respiratory syndrome (SARS)

\begin{tabular}{|c|c|}
\hline Drug & Proposed mechanism(s) \\
\hline \multicolumn{2}{|l|}{ Antiviral agents } \\
\hline Ribavirin and lopinavir/ritonavir & Anti-SARS-CoV in vitro [33] \\
\hline IFN alfacon-1 & Anti-SARS-CoV in vitro $[45]$ \\
\hline Pegylated IFN- $\alpha$ & Reduction of viral replication and pulmonary damage in macaques [46] \\
\hline Aminopeptidase $\mathrm{N}$ inhibitor & Antagonise adherence of SARS-CoV onto human cells [47] \\
\hline Glycyrrhizin & Inhibition of SARS-CoV replication in vitro [48] \\
\hline Niclosamide & Antihelminthic drug with abolition of viral antigen synthesis [43] \\
\hline Nelfinavir & $\begin{array}{l}\text { HIV-1 protease inhibitor strongly inhibited replication of the SARS-CoV } \\
\text { in vitro [49] }\end{array}$ \\
\hline Highly active antiretroviral therapy & $\begin{array}{l}\text { Observation of no SARS infection among HIV patients despite their proximity } \\
\text { to SARS cases [50] }\end{array}$ \\
\hline $\begin{array}{l}\text { Recombinant human single-chain } \\
\text { variable region fragments against } \\
\text { SARS-CoV spike protein }\end{array}$ & $\begin{array}{l}\text { Neutralisation of SARS-CoV and inhibition of syncytia formation for cells } \\
\text { expressing the spike protein in vitro [51] }\end{array}$ \\
\hline Rhinovirus $3 \mathrm{C}$ pro-inhibitor analogues & Inhibition of SARS-CoV proteinase (Mpro) responsible for viral replication [52] \\
\hline \multicolumn{2}{|l|}{ Immunomodulating drugs } \\
\hline Corticosteroid & Anti-inflammatory [53] \\
\hline Immunoglobulin & Immunomodulation [54] \\
\hline Anti-TNF- $\alpha$ & Anti-inflammatory (unpublished data) \\
\hline \multicolumn{2}{|l|}{ Miscellaneous } \\
\hline $\begin{array}{l}\text { Heparin, other anticoagulants or } \\
\text { antiplatelet agents }\end{array}$ & $\begin{array}{l}\text { ? Counteract the frequent occurrence of pulmonary thromboembolism in } \\
\text { fatal SARS [6] }\end{array}$ \\
\hline Convalescence serum from SARS patients & ? Antiviral and immunomodulating [55] \\
\hline Pentoxifylline & Anti-inflammatory, immunomodulatory and bronchodilatory effects [56] \\
\hline $\begin{array}{l}S \text {-nitroso- } N \text {-acetylpenicillamine and } \\
\text { sodium nitroprusside }\end{array}$ & $\begin{array}{l}\text { Nitric oxide donors with reduction in cytopathic effects of SARS-CoV } \\
\text { infected cells in vitro [57] }\end{array}$ \\
\hline
\end{tabular}

SARS-CoV: severe acute respiratory syndrome coronavirus; IFN: interferon; TNF: tumour necrosis factor. 


\section{Antiviral agents}

Historically, and before SARS was even defined by the WHO, early patients were treated with a broad-spectrum antiviral agent, namely ribavirin, as well as corticosteroid $[10,19]$. The very good progress and recovery of the first few patients, probably due to their young age and good premorbid health, had led to the adoption of the use of this combination as a standard anti-SARS regimen in Hong Kong and elsewhere $[10,19,20,58,59]$, amid considerable skepticism afterwards [60-62]. Ribavirin is now considered to be of no efficacy in Hong Kong as an anti-SARS agent.

The efficacy of other possible anti-SARS-CoV agents, such as anti-proteases like Kaletra (400 mg ritonavir and $100 \mathrm{mg}$ lopinavir for 14 days) in combination with ribavirin, which was shown to have some anti-SARS-CoV effects after $48 \mathrm{~h}$ incubation in vitro, has been reported recently [33]. Patients treated with Kaletra and ribavirin had significantly lower incidence of ARDS or death $(2.4 \%$ versus $28.8 \%)$, steroid usage and nosocomial infections than historical controls [33]. Whilst controlled trial data are lacking, it appears that ritonavir and lopinavir should be considered early for SARS patients, preferably in a randomised double-blind placebocontrolled clinical trial setting. Adverse reactions are significant and not infrequent, and include severe pancreatitis, diarrhoea, abdominal pain, asthenia, headache, nausea, insomnia and skin rash.

Another antiviral agent that shows considerable promise, both in vitro and in vivo, is IFN. Preliminary experience using recombinant IFNs, which are potential broad spectrum antiviral agents, revealed that IFN- $\alpha,-\beta$ and $-\gamma$ differed in antireplication effects on SARS-CoV cultured in Vero and $\mathrm{Caco} 2$ cells. IFN- $\beta$ appeared to be efficacious alone in inhibiting SARS-CoV replication in vitro [63]. In a recent screening of commercially available antiviral drugs for in vitro anti-SARS-CoV activities, only IFN subtypes $\beta-1 b, \alpha-n 1, \alpha-$ $\mathrm{n} 3$ and human leukocyte IFN- $\alpha$ exhibited complete inhibition of cytopathic effects of SARS-CoV in vitro, while nucleoside analogues, protease inhibitors, reverse transcriptase inhibitors and neuraminidase inhibitors showed no such efficacy [64]. In an open-labelled and retrospective study reported by a Canadian group, SARS patients who were treated with corticosteroids plus s.c. IFN alfacon-1 $(\mathrm{n}=9)$ had a better clinical course, in terms of need for intensive care unit admission (33.3\%), mechanical ventilation (11.1\%) and death $(0 \%)$ than their counterparts $(n=13 ; 38.5,23.1$ and $7.7 \%$, respectively). Patients treated with additional IFN alfacon-1 also appeared to recover more quickly, as manifested by a shorter time to $50 \%$ resolution of lung radiographical abnormalities, better oxygen saturation and shorter duration of supplemental oxygen therapy. These findings suggest that further investigation may be warranted to determine the role of IFN alfacon-1 as a therapeutic agent for the treatment of SARS [45].

\section{Immunomodulating agents}

The judicial use of corticosteroid therapy for deteriorating SARS patients has been shown to be associated with significant and, sometimes, dramatic radiographical and clinical recovery [65]. Since then, steroid and ribavirin were standard SARS therapy and were given upon initial diagnosis in Hong Kong in 2003. While this will no longer be practiced, and immunomodulating drugs should be given as rescue therapy, it is of note that pulse steroid therapy (generally given as methylprednisolone $250-500 \mathrm{mg}$ q.d. for 3-5 days) has been reported to have some efficacy in critically ill SARS patients. The current authors' group has evaluated the clinical and radiographical outcomes of SARS patients, who received ribavirin and different steroid regimens. Patients who received pulse steroid $\left(\mathrm{n}=17\right.$; methylprednisolone $\left.\geqslant 500 \mathrm{mg} \cdot \mathrm{day}^{-1}\right)$ as initial steroid therapy had less oxygen requirement, better radiographical outcome, and less likelihood of requiring rescue pulse steroid therapy than their counterparts $(n=55$; methylprednisolone $<500 \mathrm{mg} \cdot \mathrm{day}^{-1}$ ). Another group also reported the efficacy of pulse methylprednisolone therapy being $88.8 \%$ efficacious in improving clinical and radiographical parameters [66]. There is consensus that the use of high-dose methylprednisolone (250-500 $\mathrm{mg}$ q.d. for 3-6 days) could be lifesaving for patients presenting with deteriorating radiographical consolidation, increasing oxygen requirement and respiratory distress $\left(\right.$ rate of $\left.30 \cdot \mathrm{min}^{-1}\right)$, i.e. the syndrome of "critical SARS" [67].

As expected, the use of high-dose steroid has been associated with sepsis, particularly ventilator-associated pneumonia and even systemic fungal infection [16]. More recently, around $15 \%$ of patients with SARS were found to have magnetic resonance imaging-proven avascular necrosis $(\mathrm{AVN})$ of the hips and knees (unpublished and preliminary data, K.W. Tsang). This high incidence of AVN strongly indicates that SARS-CoV could at least be partly contributory towards its development, as the dosage and duration of steroid usage is not uncommonly used for patients suffering from rejection of transplanted organs, who do not develop such a high incidence of AVN (table 1).

Intravenous Igs have been shown to be beneficial in the treatment of many autoimmune and inflammatory conditions [68]. Pentaglobin is a commercially available i.v. Ig, specifically enriched for IgM. The higher concentration of IgM might theoretically enhance its immunomodulatory effect [69]. The current authors have administered Pentaglobin to a cohort of 12 SARS patients who did not show favourable response to treatment with pulse methylprednisolone and ribavirin therapy. There was significant improvement in radiographical scores, when compared with day 1 , on days 5,6 , and 7 after commencement of Pentaglobin treatment. Similarly, there was significant improvement in oxygen requirement, when compared with day 1 , on days 6 and 7 after commencement of Pentaglobin treatment. There were no reported adverse events attributable to Pentaglobin administration. A double-blind placebo-controlled study should therefore be considered [54].

\section{Miscellaneous agents}

Some physicians have administered serum obtained from otherwise healthy patients convalescing from SARS to other SARS patients. In total, 40 SARS patients with progressive disease after ribavirin treatment and $1.5 \mathrm{~g}$ of pulsed methylprednisolone were given either convalescent plasma $(n=19)$ obtained from recovered patients or further pulsed methylprednisolone $(n=21)$. Patients treated with convalescent plasma had a shorter hospital stay and lower mortality than their counterparts with no reported adverse effects [55]. The possible transmission of SARS-CoV (and other pathogens) to patients who could potentially suffer from SARS syndrome, but not frank SARS-CoV infection, and the theoretical potential of anti-SARS Ig being pro-inflammatory, thus aggravating the already avid pneumonitis, were among the concerns of some pulmonologists who advocate not to use this mode of therapy. The rapid deprivation of such convalescent serum, caused by its initial enthusiastic use and also rapid decline of anti-SARS-CoV IgG titre among many SARS survivors, makes this mode of potential therapy 
most unlikely to be generally available, and, thus, the conduction of controlled clinical trials not possible.

\section{Conclusions and future perspectives}

The control of severe acute respiratory syndrome is predominantly through effective public-health measures and infection-control mechanisms. The development of vaccines for severe acute respiratory syndrome is urgently needed, although there might not be adequate pharmaceutical interests and support unless there are further outbreaks! More research, including well-planned and strategically ready clinical trials, need to be undertaken in severe acute respiratory syndrome in order that we are prepared should this frightening emerging respiratory infection recurs.

\section{References}

1. World Health Organization. Summary of probable SARS cases with onset of illness from November 1, 2002 to July 31, 2003 (revised September 26, 2003). www.who.int/csr/sars/ country/table2003_09_23/en. Date last updated: December 31 2003. Date last accessed: August 132004.

2. World Health Organization. Severe acute respiratory syndrome (SARS) in Singapore (disease outbreak reported September 10, 2003). www.who.int/csr/don/2003_09_10/en. Date last updated: September 10 2003. Date last accessed: August 132004.

3. World Health Organization. Severe acute respiratory syndrome (SARS) in Taiwan, China (disease outbreak reported December 17, 2003). www.who.int/csr/don/2003_12_17/en. Date last updated: December 17 2003. Date last accessed: August 132004.

4. World Health Organization. China reports additional SARS cases: update (April 23, 2004). www.who.int/csr/don/ 2004_04_23/en. Date last updated: April 23 2004. Date last accessed: August 132004.

5. Cheng PK, Wong DA, Tong LK, et al. Viral shedding patterns of coronavirus in patients with probable severe acute respiratory syndrome. Lancet 2004; 363: 1699-1700.

6. Chong PY, Chui P, Ling AE, et al. Analysis of deaths during the severe acute respiratory syndrome (SARS) epidemic in Singapore: challenges in determining a SARS diagnosis. Arch Pathol Lab Med 2004; 128: 195-204.

7. Franks TJ, Chong PY, Chui P, et al. Lung pathology of severe acute respiratory syndrome (SARS): a study of 8 autopsy cases from Singapore. Hum Pathol 2003; 34: 743748.

8. Nicholls JM, Poon LL, Lee KC, et al. Lung pathology of fatal severe acute respiratory syndrome. Lancet 2003; 361: $1773-1778$.

9. Tse GM, To KF, Chan PK, et al. Pulmonary pathological features in coronavirus associated severe acute respiratory syndrome (SARS). J Clin Pathol 2004; 57: 260-265.

10. Tsang KW, Ho PL, Ooi GC, et al. A cluster of cases of severe acute respiratory syndrome in Hong Kong. $N$ Engl J Med 2003; 348: 1977-1985.

11. Tsang KW, Lam WK. Management of severe acute respiratory syndrome: the Hong Kong University experience. Am J Respir Crit Care Med 2003; 168: 417-424.

12. Chao CC, Tsai LK, Chiou YH, et al. Peripheral nerve disease in SARS: report of a case. Neurology 2003; 61: 1820 1821.

13. Hung EC, Chim SS, Chan PK, et al. Detection of SARS coronavirus RNA in the cerebrospinal fluid of a patient with severe acute respiratory syndrome. Clin Chem 2003; 49: 2108-2109.

14. Au A, Chan I, Li P, Chan YH, Chan J, Ng F. Correlates of psychological distress in discharged patients recovering from
SARS in Hong Kong. Int J Psychosoc Rehabil 2004; 8: 4151 .

15. Wong WM, Ho JC, Ooi GC, et al. Temporal patterns of hepatic dysfunction and disease severity in patients with SARS. JAMA 2003; 290: 2663-2665.

16. Wang H, Ding Y, Li X, Yang L, Zhang W, Kang W. Fatal aspergillosis in a patient with SARS who was treated with corticosteroids. N Engl J Med 2003; 349: 507-508.

17. World Health Organization. Case definitions for surveillance of severe acute respiratory syndrome (SARS) (revised May 1, 2003). www.who.int/csr/sars/casedefinition/en. Date last updated: May 1 2003. Date last accessed: August 132004.

18. Center for Disease Prevention and Control. Severe acute respiratory syndrome (SARS). Diagnosis/evaluation. February 6, 2004. www.cdc.gov/ncidod/sars/diagnosis.htm. Date last updated: February 6 2004. Date last accessed: August 132004.

19. Lee $\mathrm{N}$, Hui $\mathrm{D}, \mathrm{Wu} \mathrm{A}$, et al. A major outbreak of severe acute respiratory syndrome in Hong Kong. New Engl J Med 2003; 348: 1986-1994.

20. Poutanen SM, Low DE, Henry B, et al. National Microbiology Laboratory, Canada; Canadian Severe Acute Respiratory Syndrome Study Team. Identification of severe acute respiratory syndrome in Canada. N Engl J Med 2003; 348: 1995-2005.

21. Booth CM, Matukas LM, Tomlinson GA, et al. Clinical features and short-term outcomes of 144 patients with SARS in the greater Toronto area. JAMA 2003; 289: 2801-2809.

22. Peiris JS, Chu CM, Cheng VC, et al. HKU/UCH SARS Study Group. Clinical progression and viral load in a community outbreak of coronavirus associated SARS pneumonia: a prospective study. Lancet 2003; 361: 17671772.

23. Rainer TH, Chan PK, Ip M, et al. The spectrum of severe acute respiratory syndrome-associated coronavirus infection. Ann Intern Med 2004; 140: 614-619.

24. Lam MF, Ooi GC, Lam B, et al. An indolent case of severe acute respiratory syndrome. Am J Respir Crit Care Med 2004; 169: 125-128.

25. Hon KL, Leung CW, Cheng WT, et al. Clinical presentations and outcome of severe acute respiratory syndrome in children. Lancet 2003; 361: 1701-1703.

26. Wang TL, Jang TN, Huang CH, et al. Establishing a clinical decision rule of severe acute respiratory syndrome at the emergency department. Ann Emerg Med 2004; 43: 17-22.

27. Chen SY, Su CP, Ma MH, et al. Predictive model of diagnosing probable cases of severe acute respiratory syndrome in febrile patients with exposure risk. Ann Emerg Med 2004; 43: 1-5.

28. Sun Y, Yao W, Wang X, et al. Clinical diagnostic approach to severe acute respiratory syndrome: an institution's experience. Chin Med J (Engl) 2003; 116: 1464-1466.

29. Wong KT, Antonio GE, Hui DS, et al. Severe acute respiratory syndrome: radiographic appearances and pattern of progression in 138 patients. Radiology 2003; 228: 401-406.

30. Ooi CG, Khong PL, Ho JC, et al. Severe acute respiratory syndrome: radiographic evaluation and clinical outcome measures. Radiology 2003; 229: 500-506.

31. Ooi CG, Khong PL, Lam B, et al. Severe acute respiratory syndrome: relationship between radiologic and clinical parameters. Radiology 2003; 229: 492-499.

32. Ooi GC, Daqing M. SARS: radiological features Respirology 2003; 8: S15-S19.

33. Chu CM, Leung YY, Hui JY, et al. Spontaneous pneumomediastinum in patients with severe acute respiratory syndrome. Eur Respir J 2004; 23: 802-804.

34. Hsieh SC, Chan WP, Chien JC, et al. Radiographic appearance and clinical outcome correlates in 26 patients with severe acute respiratory syndrome. AJR Am J Roentgenol 2004; 182: 1119-1122.

35. Hui DS, Wong PC, Wang C. SARS: clinical features and diagnosis. Respirology 2003; 8: S20-S24. 
36. Chan KH, Poon LL, Cheng VC, et al. Detection of SARS coronavirus in patients with suspected SARS. Emerg Infect Dis 2004; 10: 294-299.

37. Poon LL, Wong OK, Chan KH, et al. Rapid diagnosis of a coronavirus associated with severe acute respiratory syndrome (SARS). Clin Chem 2003; 49: 953-955.

38. Yam WC, Chan KH, Poon LL, et al. Evaluation of reverse transcription-PCR assays for rapid diagnosis of severe acute respiratory syndrome associated with a novel coronavirus. $J$ Clin Microbiol 2003; 41: 4521-4524.

39. Jiang SS, Chen TC, Yang JY, et al. Sensitive and quantitative detection of severe acute respiratory syndrome coronavirus infection by real-time nested polymerase chain reaction. Clin Infect Dis 2004; 38: 293-296.

40. Poon LL, Chan KH, Wong OK, et al. Detection of SARS coronavirus in patients with severe acute respiratory syndrome by conventional and real-time quantitative reverse transcription-PCR assays. Clin Chem 2004; 50: 67-72.

41. Poon LL, Wong BW, Chan KH, et al. A one step quantitative RT-PCR for detection of SARS coronavirus with an internal control for PCR inhibitors. J Clin Virol 2004; 30: 214-217.

42. Poon LL, Chan KH, Wong OK, et al. Early diagnosis of SARS coronavirus infection by real time RT-PCR. $J$ Clin Virol 2003; 28: 233-238.

43. Wu HS, Chiu SC, Tseng TC, et al. Serologic and molecular biologic methods for SARS-associated coronavirus infection, Taiwan. Emerg Infect Dis 2004; 10: 304-310.

44. Ng EK, Hui DS, Chan KC, et al. Quantitative analysis and prognostic implication of SARS coronavirus RNA in the plasma and serum of patients with severe acute respiratory syndrome. Clin Chem 2003; 49: 1976-1980.

45. Loutfy MR, Blatt LM, Siminovitch KA, et al. Interferon alfacon-1 plus corticosteroids in severe acute respiratory syndrome: a preliminary study. JAMA 2003; 290: 3222-3228.

46. Haagmans BL, Kuiken $\mathrm{T}$, Martina BE, et al. Pegylated interferon-alpha protects type 1 pneumocytes against SARS coronavirus infection in macaques. Nat Med 2004; 10: 290293.

47. Kontoyiannis DP, Pasqualini R, Arap W. Aminopeptidase $\mathrm{N}$ inhibitors and SARS. Lancet 2003; 361: 1558.

48. Cinatl J, Morgenstern B, Bauer G, Chandra P, Rabenau H, Doerr HW. Glycyrrhizin, an active component of liquorice roots, and replication of SARS-associated coronavirus. Lancet 2003; 361: 2045-2046.

49. Yamamoto N, Yang R, Yoshinaka Y, et al. HIV protease inhibitor nelfinavir inhibits replication of SARS-associated coronavirus. Biochem Biophys Res Commun 2004; 318: 719725.

50. Chen XP, Cao Y. Consideration of highly active antiretroviral therapy in the prevention and treatment of severe acute respiratory syndrome. Clin Infect Dis 2004; 38: 1030-1032.

51. Sui J, Li W, Murakami A, et al. Potent neutralization of severe acute respiratory syndrome (SARS) coronavirus by a human $\mathrm{mAb}$ to $\mathrm{S} 1$ protein that blocks receptor association. Proc Natl Acad Sci U S A 2004; 101: 2536-2541.
52. Anand K, Ziebuhr J, Wadhwani P, Mesters JR, Hilgenfeld R. Coronavirus main proteinase (3CLpro) structure: basis for design of anti-SARS drugs. Science 2003; 300: 1763-1767.

53. Ho JC, Ooi GC, Mok TY, et al. High-dose pulse versus nonpulse corticosteroid regimens in severe acute respiratory syndrome. Am J Respir Crit Care Med 2003; 168: 1449-1456.

54. Ho JCM, Wu AY, Lam B, et al. Pentaglobin in steroidresistant severe acute respiratory syndrome. Int $J$ Tuberc Lung Dis 2004; (In press).

55. Soo YO, Cheng Y, Wong R, et al. Retrospective comparison of convalescent plasma with continuing high-dose methylprednisolone treatment in SARS patients. Clin Microbiol Infect 2004; 10: 676-678.

56. Bermejo Martin JF, Jimenez JL, Munoz-Fernandez A. Pentoxifylline and severe acute respiratory syndrome (SARS): a drug to be considered. Med Sci Monit 2003; 9: SR29-SR34.

57. Keyaerts E, Vijgen L, Chen L, Maes P, Hedenstierna G, Van Ranst M. Inhibition of SARS-coronavirus infection in vitro by S-nitroso-N-acetylpenicillamine, a nitric oxide donor compound. Int $J$ Infect Dis 2004; 8: 223-226.

58. So LK, Lau AC, Yam LY, et al. Development of a standard treatment protocol for severe acute respiratory syndrome. Lancet 2003; 361: 1615-1617.

59. Chan-Yeung M, Ooi GC, Hui DS, Ho PL, Tsang KW. Severe acute respiratory syndrome. Int J Tuberc Lung Dis 2003; 7: 1117-1130.

60. Cyranoski D. Critics slam treatment for SARS as ineffective and perhaps dangerous. Nature 2003; 423: 4.

61. Wenzel RP, Edmond MB. Managing SARS amidst uncertainty. N Engl J Med 2003; 348: 1947-1948.

62. Knowles SR, Phillips EJ, Dresser L, Matukas L. Common adverse events associated with the use of ribavirin for severe acute respiratory syndrome in Canada. Clin Infect Dis 2003; 37: 1139-1142.

63. Cinatl J, Morgenstern B, Bauer G, Chandra P, Rabenau H, Doerr HW. Treatment of SARS with human interferons. Lancet 2003; 362: 293-294.

64. Tan EL, Ooi EE, Lin CY, et al. Inhibition of SARS coronavirus infection in vitro with clinically approved antiviral drugs. Emerg Infect Dis 2004; 10: 581-586.

65. Zhong NS, Zeng GQ. Our strategies for fighting severe acute respiratory syndrome (SARS). Am J Respir Crit Care Med 2003; 168: 7-9.

66. Sung JJ, Wu A, Joynt GM, et al. Severe acute respiratory syndrome: report of treatment and outcome after a major outbreak. Thorax 2004; 59: 414 420.

67. Tsang K, Zhong NS. SARS: pharmacotherapy. Respirology 2003; 8: S25-S30.

68. Dwyer JM. Manipulating the immune system with immune globulin. N Engl J Med 1992; 326: 107-116.

69. Nachbaur D, Herold M, Gächter A, Niederwieser D. Modulation of alloimmune response in vitro by an IgM-enriched immunoglobulin preparation (Pentaglobin). Immunology 1998; 94: 279-283. 